\title{
Student Attitudes When Solving Homework Problems that Reverse Engineer YouTube Videos
}

\section{Uchenna Asogwa, The University of Toledo}

Uchenna Asogwa is a graduate student of Chemical Engineering at the University of Toledo. He earned a B.S. degree from the University of Benin, Nigeria in chemical engineering. His current research involves the reverse engineering online videos as well as rheology of complex fluids.

\section{Prof. Matthew W Liberatore, The University of Toledo}

Matthew W. Liberatore is a Professor of Chemical Engineering at the University of Toledo. He earned a B.S. degree from the University of Illinois at Chicago and M.S. and Ph.D. degrees from the University of Illinois at Urbana-Champaign, all in chemical engineering. His current research involves the rheology of complex fluids as well as active learning, reverse engineering online videos, and interactive textbooks. His website is: http://www.utoledo.edu/engineering/chemical-engineering/liberatore/

\section{Mr. Timothy Ryan Duckett, The University of Toledo}

T. Ryan Duckett is a research associate with Acumen Research and Evaluation, LLC., a program evaluation and grant writing company that specializes in STEM and early childhood education. He is a $\mathrm{PhD}$ student in the Research and Measurement department at the University of Toledo.

\section{Dr. Gale A Mentzer, Acumen Research and Evaluation, LLC}

Gale A. Mentzer, PhD, the owner and director of Acumen Research and Evaluation, LLC, has been a professional program evaluator since 1998. She holds a PhD in Educational Research and Measurement from The University of Toledo and a Master of Arts in English Literature and Language-a unique combination of specializations that melds quantitative and qualitative methodologies. She and has extensive experience in the evaluation of projects focused on STEM education including evaluations of several multi-million dollar federally funded projects. Previously she taught graduate level courses for the College of Education at The University of Toledo in Statistics, Testing and Grading, Research Design, and Program Evaluation. 


\title{
Student Attitudes When Solving Homework Problems that Reverse Engineer YouTube Videos
}

\begin{abstract}
Problem solving is a vital skill required to be successful in many engineering industries. One way for students to practice problem solving is through solving homework problems. However, solutions manuals for textbook problems are usually available online, and students can easily default to copying from solution manual. To address the solution manual dilemma and promote better problem-solving ability, this study utilizes novel homework problems that integrate a video component as an alternative to text-only, textbook problems. Building upon research showing visuals promote better learning, YouTube videos are reversed engineered by students to create new homework problems. Previous studies have catalogued student-written problems in a material and energy balance course, which are called YouTube problems. In this study, textbook homework problems were replaced with student-written YouTube problems. We additionally focused on examining learning attitudes after students solve YouTube problems. Data collection include attitudinal survey responses using a validated instrument called CLASS (Colorado Learning Attitudes about Science Survey). Students completed the survey at the beginning and end of the course. Analysis compared gains in attitudes for participants in the treatment groups. Mean overall attitude of participants undergoing YouTube intervention was improved by a normalized gain factor of 0.15 with a small effect size (Hedge's $g=0.35$ ). Improvement was most prominent in attitudes towards personal application and relation to real world connection with normalized gain of 0.49 and small effect size (Hedge's $g=0.38$ ).
\end{abstract}

\section{Introduction}

Complex problem-solving skills are valued in today's workplace and predicted to be the most prevalent type of skill needed to thrive in the 2030 workforce [1]. Most instructional approaches limit students' ability to transfer learning by focusing on only course-specific information. Recent efforts incorporating Accrediting Board for Engineering and Technology (ABET) standards that emphasize problem solving and knowledge of current issues found that infusing real world situations into engineering education helps students' understanding become more integrated $[2,3]$. Therefore, tying engineering problem solving with real world environments aligns well with current and future workforce needs.

In addition to integrating real world situations in teaching, senses play a vital role in learning. Specifically, vision is the most important sense when creating both short term and long-term learning [4]. Visual learning methods open new ways of problem solving, thinking, as well as enhance the education and practice of science and engineering [5-11]. Furthermore, the seemingly limitless material on the Internet, and particularly YouTube videos, provide an array of contexts to connect engineering fundamentals to visual situations, which can be motivating and interesting. Therefore, the engagement and productive learning from searching for, identifying, watching, and translating YouTube videos ties in well with cutting-edge research in neuroscience and learning science $[4,12,13]$. 
The chemical engineering curriculum traditionally begins with a course in material and energy balances (MEB). MEB introduces the principles and techniques used in chemical engineering. MEB involves stoichiometry, material balances, and energy balances, i.e., calculations that require basic concepts of mathematics, physics and chemistry in solving problems. Material and energy balances can be categorized as a "comprehension" course. The students must learn to read problem statements, construct a picture of the system, and logically solve the problem [14-19].

Almost all current undergraduate students, including those studying MEB, began interacting with digital technology at a young age and are often referred to as digital natives [20]. Some learning differences are being identified between digital natives and past generations. In many cases, digital natives show a preference for visual compared to textual modes of learning, are strongly motivated by projects having a real-world component, and possess shorter attention spans [21]. Moreover, common tasks today, including solving homework problems, revolve around utilization of devices such as cell phones, tablets, and computers to assist in finding course-related information.

While homework problems from textbooks are designed to allow engineering students to practice problem solving, easy accessibility of solution manual has created an issue [14, 22]. Besides being an issue of academic integrity, copying solutions rather than putting effort into learning course concepts and developing problem-solving skills could inhibit success [14]. In fact, problemsolving skills has been identified as a major concern for students learning MEB [19].

YouTube pedagogy has students actively creating new course content, which falls under the guise of research-based best practices commonly called active learning [23-25]. The YouTube pedagogy discussed here, started as a way to introduce and engage students in various courses. Originally called YouTube Fridays, the first five minutes of Friday class sessions were dedicated to course related videos selected by a group of students [26]. In subsequent semesters, students selected YouTube videos and created engineering estimate problems related to the course material. The vast majority of survey feedback about YouTube Fridays was positive and students felt they had a better understanding of the course topic and even felt confident solving problems. Also, students reported the ability to relate course to real world phenomena since YouTube pedagogy provided students a mechanism to apply classroom concepts to open-ended, real world situations [27-30].

While YouTube pedagogy possess the potential to engage students and improve problem solving abilities, more research is needed. For example, many researchers have indicated that teacher attitudes and effort required in a course influence students' attitude [31-34]. The importance of attitudes has been increasingly recognized in recent years; several studies show how positive attitudes toward science lead students to pursue science careers [35]. Learning attitudes have a significant positive correlation with academic achievement and self-directed learning ability [36, 37]. Furthermore, teaching strategy can influence students' attitudes which consequently affects learning gains or outcomes [38]. Since study have shown that integration of technology possess some correlation with attitude students [39], it is necessary to assess students attitudes when implementing YouTube pedagogy.

As a result of the importance of attitudes in learning, many researchers have devised various strategies of measuring attitudes. Tools for measuring attitudes could be categorized as qualitative, quantitative tools or a combination of both [40]. While qualitative analysis tools, such as student interviews, provide rich data that can reveal new insights and allow for flexibility and clarification 
of students' ideas, analyzing written comments or transcripts can be very labor intensive. Quantitative analysis tools, such as surveys, can allow for easier compilation of student responses that attach numerical scores to responses. One of such quantitative survey tools that has been validated and become common among researchers is the Colorado Learning Attitudes for Science Survey (CLASS) [38, 41, 42] The current study evaluates the impact of YouTube pedagogy on students' learning attitudes using CLASS. Experimental set up, data collection and analysis resulting from CLASS encompass the rest of this paper.

\section{Materials and Methods}

The central hypothesis is that student-generated YouTube problems promote better problemsolving skills than traditional textbook problems, which has been discussed previously [30]. This research examines the effects of teaching techniques, namely the YouTube pedagogy, on students' attitudes towards learning. Through survey responses from one cohort during the 2017-2018 academic year, we examine a treatment and control group (Table 1).

Table 1. Summary of problem assignment to treatment and control group.

\begin{tabular}{lcccc}
\hline Cohorts & $\begin{array}{c}\text { YouTube } \\
\text { Problems }\end{array}$ & $\begin{array}{c}\text { Textbook } \\
\text { Problems }\end{array}$ & $\begin{array}{c}\text { Created } \\
\text { YouTube } \\
\text { Problems }\end{array}$ & Class size \\
\hline Treatment & 9 & 10 & 1 & 90 \\
Control & 0 & 10 & 0 & 23 \\
\hline
\end{tabular}

Twenty-three students at a private university served as control group, who solved 10 homework problems from a textbook as part of this project (Table 1). A similar group of 90 students from a large public university solved 9 YouTube problems in addition to the same 10 textbook problems as the control group. Students in the treatment group were also required to create YouTube problems as part of homework activities. Both groups studied the same course content, used the same textbook, and solved many other homework problems from the textbook.

For participants in the treatment group, homework assignments, normally 3 to 5 problems per week, varied between only textbook problems, only YouTube problems, and a combination of textbook and YouTube problems. During the initial weeks of the study, both groups solved only textbook problems as a measure of group equivalency. Since both treatment and control group use the same textbook [43], common problems were assigned.

The Colorado Learning Attitudes about Science Survey (CLASS) was administered in a pre/post participation design. Although CLASS was initially designed for physics, several studies have variations for chemistry, biology, astronomy and math [42,44]. This study utilized version 3 of CLASS for Physics, while the project team modified survey questions to match course content. The original version of CLASS was on a five-point Likert scale (strongly agree, agree, neutral, disagree to strongly disagree), but has been modified for the current project to a four-point Likert scale by eliminating the neutral response. Instructors tried to alleviate student's anxiety by informing students that correctness of the response will not affect their grades. 
Because the CLASS has been successfully adapted from physics to both chemistry and biology, the CLASS was modified following the recommendations of Adams et al. 2008 [42]. Essentially, the CLASS tool measures attitudes about a science subject so adaptation was simply a matter of changing the science topic from Physics to Engineering and then assuring that the items remained meaningful. Two chemical engineering $(\mathrm{ChE})$ faculty reviewed the instrument to provide content validity and concurrent validity evidence was provided by comparing responses of novice $\mathrm{ChE}$ with advanced ChE students.

Table 2. Statements in the version 3 of CLASS with corresponding desired responses [42].

\begin{tabular}{|c|c|c|}
\hline \# & Statements & $\begin{array}{l}\text { Expert } \\
\text { response }\end{array}$ \\
\hline 1 & $\begin{array}{l}\text { A significant problem in learning engineering is being able to memorize all the } \\
\text { information I need to know. }\end{array}$ & Disagree \\
\hline 2 & $\begin{array}{l}\text { When I am solving an engineering problem, I try to decide what would be a } \\
\text { reasonable value for the answer. }\end{array}$ & Agree \\
\hline 3 & I think about the engineering I experience in everyday life. & Agree \\
\hline 4 & It is useful for me to do lots and lots of problems when learning engineering. & NA \\
\hline 5 & $\begin{array}{l}\text { After I study a topic in engineering and feel that I understand it, I have } \\
\text { difficulty solving problems on the same topic. }\end{array}$ & Disagree \\
\hline 6 & Knowledge in engineering consists of many disconnected topics. & Disagree \\
\hline 7 & $\begin{array}{l}\text { As engineers learn more, most engineering ideas we use today are likely to } \\
\text { be proven wrong. }\end{array}$ & NA \\
\hline 8 & $\begin{array}{l}\text { When I solve an engineering problem, I locate an equation that uses the } \\
\text { variables given in the problem and plug in the values. }\end{array}$ & Disagree \\
\hline 9 & I find that reading the text in detail is a good way for me to learn engineering. & NA \\
\hline 10 & $\begin{array}{l}\text { There is usually only one correct approach to solving an engineering } \\
\text { problem. }\end{array}$ & Disagree \\
\hline 11 & I am not satisfied until I understand why something works the way it does. & Agree \\
\hline 12 & I cannot learn engineering if the teacher does not explain things well in class. & Disagree \\
\hline 13 & $\begin{array}{l}\text { I do not expect engineering equations to help my understanding of the ideas; } \\
\text { they are just for doing calculations. }\end{array}$ & Disagree \\
\hline 14 & $\begin{array}{l}\text { I study engineering to learn knowledge that will be useful in my life outside of } \\
\text { school. }\end{array}$ & Agree \\
\hline 15 & $\begin{array}{l}\text { If I get stuck on an engineering problem my first try, I usually try to Figure out } \\
\text { a different way that works. }\end{array}$ & Agree \\
\hline 16 & Nearly everyone is capable of understanding engineering if they work at it. & Agree \\
\hline 17 & $\begin{array}{l}\text { Understanding engineering basically means being able to recall something } \\
\text { you've read or been shown. }\end{array}$ & Disagree \\
\hline 18 & $\begin{array}{l}\text { There could be two different correct values to an engineering problem if I use } \\
\text { two different approaches. }\end{array}$ & Disagree \\
\hline 19 & To understand engineering, I discuss it with friends and other students. & Agree \\
\hline 20 & $\begin{array}{l}\text { I do not spend more than five minutes stuck on an engineering problem } \\
\text { before giving up or seeking help from someone else. }\end{array}$ & Disagree \\
\hline 21 & $\begin{array}{l}\text { If I don't remember a particular equation needed to solve a problem on an } \\
\text { exam, there's nothing much I can do (legally) to come up with it. }\end{array}$ & Dis \\
\hline 22 & $\begin{array}{l}\text { If I want to apply a method used for solving one engineering problem to } \\
\text { another problem, the problems must involve very similar situations. }\end{array}$ & Dis \\
\hline
\end{tabular}




\begin{tabular}{|c|c|c|}
\hline 23 & $\begin{array}{l}\text { In doing an engineering problem, if my calculation gives a result very different } \\
\text { from what l'd expect, l'd trust the calculation rather than going back through } \\
\text { the problem. }\end{array}$ & Disagree \\
\hline 24 & $\begin{array}{l}\text { In engineering, it is important for me to make sense out of formulas before I } \\
\text { can use them correctly. }\end{array}$ & Agree \\
\hline 25 & I enjoy solving engineering problems. & Agree \\
\hline 26 & $\begin{array}{l}\text { In engineering, mathematical formulas express meaningful relationships } \\
\text { among measurable quantities. }\end{array}$ & Agree \\
\hline 27 & $\begin{array}{l}\text { It is important for the government to approve new scientific ideas before they } \\
\text { can be widely accepted. }\end{array}$ & Disagree \\
\hline 28 & Learning engineering changes my ideas about how the world works. & Agree \\
\hline 29 & To learn engineering, I only need to memorize solutions to sample problems. & Disagree \\
\hline 30 & $\begin{array}{l}\text { Reasoning skills used to understand engineering can be helpful to me in my } \\
\text { everyday life. }\end{array}$ & Agree \\
\hline 31 & $\begin{array}{l}\text { We use this statement to discard the survey of people who are not reading } \\
\text { the questions. Please select strongly agree-option } 4 \text { for this question to } \\
\text { preserve your answers. }\end{array}$ & $\begin{array}{l}\text { Strongly } \\
\text { agree } \\
\text { only }\end{array}$ \\
\hline 32 & $\begin{array}{l}\text { Spending a lot of time understanding where formulas come from is a waste of } \\
\text { time. }\end{array}$ & Disagree \\
\hline 33 & $\begin{array}{l}\text { I find carefully analyzing only a few problems in detail is a good way for me to } \\
\text { learn engineering. }\end{array}$ & NA \\
\hline 34 & I can usually Figure out a way to solve engineering problems. & Agree \\
\hline 35 & $\begin{array}{l}\text { The subject of engineering has little relation to what I experience in the real } \\
\text { world. }\end{array}$ & Disagree \\
\hline 36 & $\begin{array}{l}\text { There are times I solve an engineering problem more than one way to help } \\
\text { my understanding. }\end{array}$ & Agree \\
\hline 37 & $\begin{array}{l}\text { To understand engineering, I sometimes think about my personal } \\
\text { experiences and relate them to the topic being analyzed. }\end{array}$ & Agree \\
\hline 38 & It is possible to explain engineering ideas without mathematical formulas. & Agree \\
\hline 39 & $\begin{array}{l}\text { When I solve an engineering problem, I explicitly think about which } \\
\text { engineering ideas apply to the problem. }\end{array}$ & Agree \\
\hline 40 & $\begin{array}{l}\text { If I get stuck on an engineering problem, there is no chance l'll figure it out on } \\
\text { my own. }\end{array}$ & Disagree \\
\hline 41 & $\begin{array}{l}\text { It is possible for engineers to carefully perform the same experiment and get } \\
\text { two very different results that are both correct. }\end{array}$ & NA \\
\hline 42 & $\begin{array}{l}\text { When studying engineering, I relate the important information to what I } \\
\text { already know rather than just memorizing it the way it is presented. }\end{array}$ & Agree \\
\hline
\end{tabular}

CLASS consisted of 42 survey questions (Table 2). CLASS usually required less than 10 minutes for respondents to complete. To streamline analysis, strongly agree and agree were considered to be the same selection and similarly, disagree and strongly disagree were considered to be the same selection [42]. The overall score included 36 statements out of the total 42 statements in the CLASS; six questions were not analyzed. Five statements with responses as NA (not applicable) have no consensus expert response. Five statements with no consensus response plus a statement for attention check do not contribute to the CLASS score [42]. Question 31 is an attention-check, and surveys with incorrect answers for question 31 were removed from further analysis. 
Table 3. Categories of survey questions from CLASS [41].

\begin{tabular}{lcc}
\hline Categories & $\begin{array}{c}\text { Statements } \\
\text { within category }\end{array}$ & $\begin{array}{c}\text { Number of } \\
\text { statements }\end{array}$ \\
\hline Personal Application and Relation to & $3,14,25,28,30,37$ & 6 \\
Real World Connection & $5,21,22,34,40$ & 5 \\
Problem Solving/Learning & $23,24,29,32$ & 4 \\
Sense Making/ Effort & $4,7,9,31,33,41$ & 6 \\
Not Scored &
\end{tabular}

Leveraging earlier work by Douglas et al, CLASS statements were grouped into 3 categories: Personal application and relation to real world connection, Problem Solving/learning, Sensemaking/Effort (Table 3) [41]. Each category consisted of four to six statements that describe a specific aspect of student thinking. These subgroupings of the CLASS included 15 of the 42 statements unlike the original version of CLASS where subcategories included 27 statements [42]. Therefore, CLASS scores for overall learning attitude and three sub-categories will be analyzed.

CLASS score was determined for each student as the percentage of responses that a student agrees with the experts' responses. For example, statement 1 in CLASS survey states "A significant problem in learning engineering is being able to memorize all the information I need to know." The desired response for question 1 was either disagree or strongly disagree. If a participant disagrees or strongly disagrees with statement 1 , the participant would earn 1 point. However, if a participant response agreed or strongly agreed with statement 1 , participant scored 0 points. CLASS scores for each participant represented number of times a participant gave a desired response expressed as a percentage. Analysis compared group CLASS scores of students at the beginning and end of course. Normalized gain and effect size analysis quantified magnitude of change in learning attitudes of participants. Samples in current study are dissimilar in size, therefore, Hedges' g was adopted since it measures effect size weighted according to the relative size of each sample [45].

\section{Results and Discussion}

First, students' responses to CLASS are analyzed for the treatment group broadly using box plots. Next, an assessment of any substantial differences in mean CLASS scores between beginning and end of semester will be quantified. Two tailored t-tests, normalized gains, and effect size analysis quantify the significance of changes in CLASS scores. 

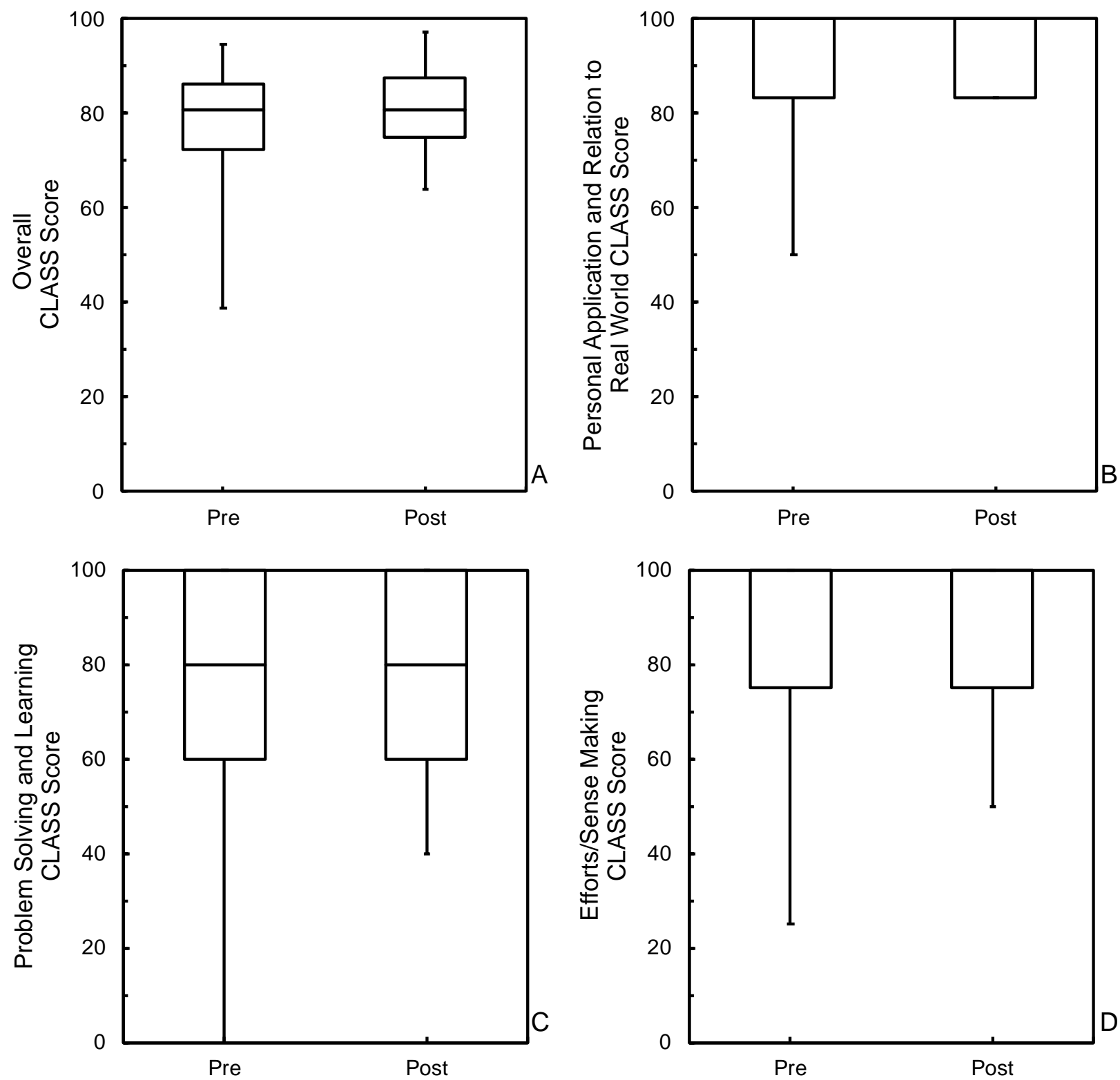

Figure 1. Box plots comparing CLASS score for participants in treatment group at the beginning $(\mathrm{n}=72)$ and towards the end $(\mathrm{n}=19)$ of the semester. $\mathrm{A}=$ Overall, $\mathrm{B}=$ Personal Application and Relation to Real World, C = Problem Solving and Learning, D = Efforts/Sense Making.

CLASS scores denote a percentage of statements that participants gave a desired response. Box plots (Figure 1) provide a visual representation for the distribution of treatment students' overall CLASS scores, including minimum, first quartile, median, third quartile, and maximum scores. The whiskers extending from the box signify the minimum and maximum overall CLASS score earned. Throughout the duration of the semester, $50 \%$ of the treatment group maintained an overall CLASS score of at least 81 (Figure 1A). In fact, $75 \%$ of the population improved their overall CLASS score from at least 72 to 75 . Similarly, $25 \%$ of student population progressed from CLASS scores at least 86 to 88 . The range in overall CLASS scores was 56 in the pre-setting, which dropped to 33 at the end of the semester (40\%). In addition, the interquartile range decreased over 
the semester from 14 to 13 , suggesting that not only were students scoring higher but more consistently with their peers.

Next, CLASS responses from treatment group were analyzed on each of the CLASS' subscales. Similar to the overall CLASS scores, the treatment group displayed high scores on the Personal Application subscale, with $75 \%$ of the population maintaining a CLASS score of at least 83 throughout the duration of the semester (Figure 1B). A ceiling effect was observed with $50 \%$ of the population exhibiting complete sync with expert beliefs on this subscale throughout the semester. The range of scores decreased from 50 to 17 (66\%) over the semester indicating greater consistency in population attitudes toward Personal Application of chemical engineering material to the real world.

Similar trends were found regarding students' attitudes toward the effort involved in making sense of the chemical engineering material (i.e., the Effort subscale, displayed in Figure 1D). Once again, $50 \%$ of the treatment students aligned completely with the responses of experts regarding the effort involved in chemical engineering. Wide range in overall CLASS scores was measured in the beginning (80) which dropped towards the end of the semester by $40 \%$.

Regarding the role of problem solving and learning in chemical engineering, $50 \%$ of the treatment group maintained at least an overall CLASS score of 80 throughout the duration of the semester (Figure 1C). Although the top $25 \%$ of the population aligned exactly expert beliefs, the large range indicates variance in attitudes. Although the range decreased by $40 \%$ over the semester, a broad range of attitudes toward problem solving persisted. 

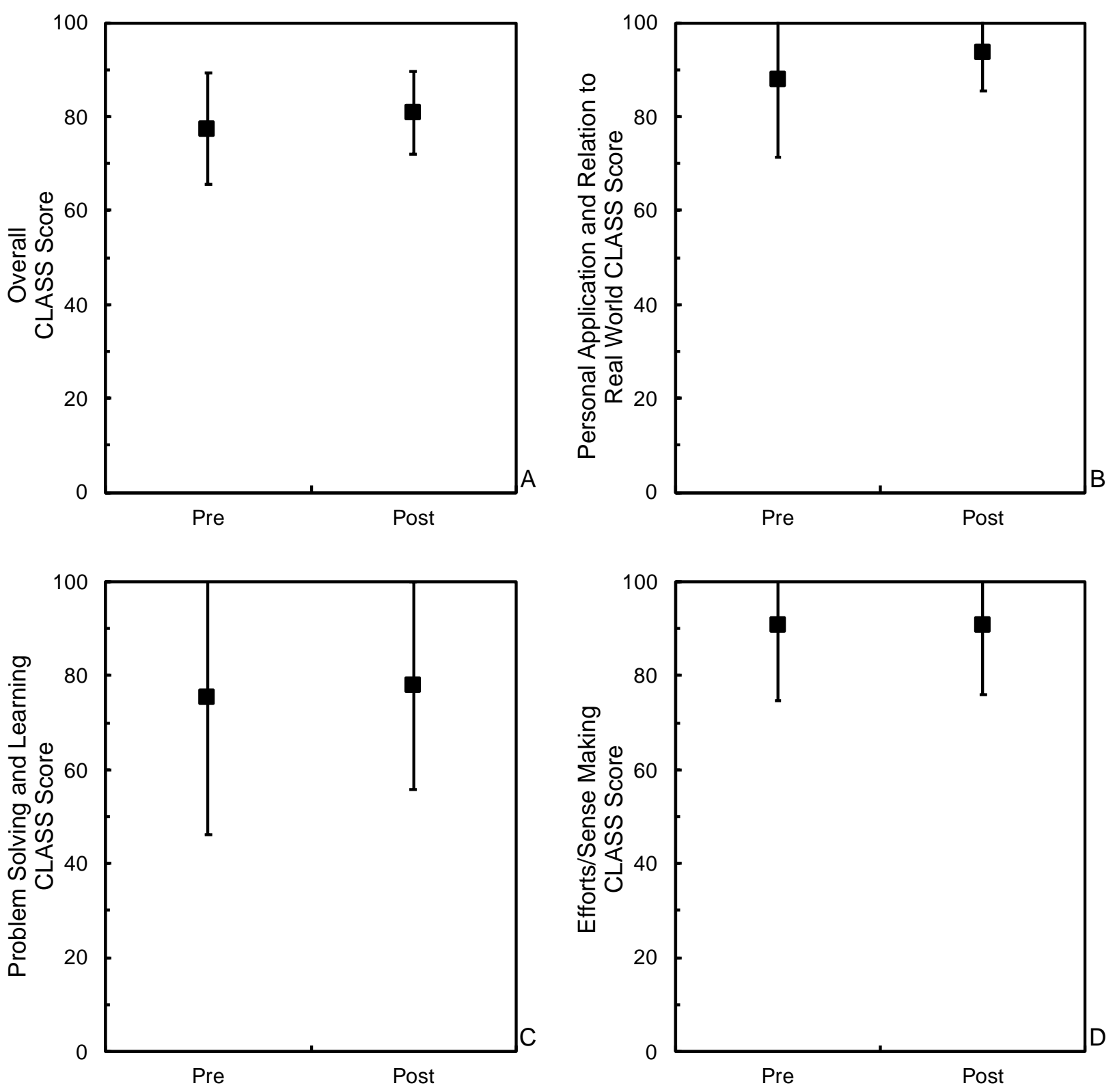

Figure 2. Average CLASS score for participants in treatment group at the beginning $(n=72)$ and towards the end $(n=19)$ of the semester. $A=$ Overall, $B=$ Personal Application and Relation to Real World, C=Problem Solving Learning, D=Efforts/Sense Making.

Focusing the analysis, mean CLASS scores with whiskers denoting standard deviations allow pre/post trends to be captured (Figure 2). Overall, the treatment group displayed a 5\% positive shift in mean overall learning attitude assessed within a 15-week semester (Figure 2A). Correspondingly, positive shifts of 7 (Figure 2B) and 4\% (Figure 2C) were noted in the Personal Application and Problem Solving categories, respectively No change was measured for attitudes relating to sense making/effort, which might be as a result of ceiling effect where participants were extremely in agreement with expert belief that no shift in belief is noted (Figure 2D). 
Standard deviation measured for overall attitudes decreased from 12 to $9 \%$ over the semester indicating greater consistency in population attitudes. Similar decrease in standard deviation was noted for every category in CLASS. In fact, shrinkage in standard deviation was very prominent (53\%) in attitude toward Personal Application and Real World Connection. Smaller deviations measured towards the end of the semester indicate a consensus in learning attitudes of students participating in the YouTube intervention.

Two tailored t-tests were conducted and normalized gains and effect size calculated to quantify statistical differences in the treatment group from the beginning to the end of the semester. As displayed in Table 4, although students showed gains in the overall CLASS score as well as the Personal Application, Problem Solving, and Effort subscales, none of the gains were significant ( $p$ $<0.05)$.

Table 4. Pre and post CLASS averages and standard deviation with additional statistical parameters $(\mathrm{n}=72$ for pre and 19 for post $)$.

\begin{tabular}{lccccc} 
Categories & Pre & Post & p & $\begin{array}{c}\text { Normalized } \\
\text { gain }\end{array}$ & $\begin{array}{c}\text { Effect size } \\
(\mathrm{g})\end{array}$ \\
\hline $\begin{array}{l}\text { Overall } \\
\text { Personal Application and }\end{array}$ & $77 \pm 12$ & $81 \pm 9$ & 0.18 & 0.15 & 0.35 \\
Relation to Real World & & & & & \\
Connection & $88 \pm 17$ & $94 \pm 8$ & 0.14 & 0.49 & 0.38 \\
Problem Solving/Learning & $75 \pm 29$ & $78 \pm 22$ & 0.67 & 0.11 & 0.11 \\
Sense Making/ Effort & $91 \pm 16$ & $91 \pm 15$ & 1 & 0.02 & 0 \\
\hline
\end{tabular}

Amongst all three categories of CLASS, participants displayed the lowest level of alignment with experts regarding the Problem Solving category. Since four of the five statements in the Problem Solving category expect students to disagree, students might have been biased by the negative wording. Specifically, on item 22, only $61 \%$ of students responded favorably at the start of the semester which further dropped to $53 \%$ towards the end of the semester. Item 22 posited that chemical engineering problems need to have very similar situations in order to apply a method for solving them (Table 2). Since many students agreed with this statement, one semester of exposure in the field of chemical engineering may not be sufficient to develop robust strategies for applying problem solving strategies in diverse situations.

Within group analysis measured changes in attitudes by comparing mean CLASS scores earned in a pre and post survey. Normalized gain and effect size analyses provided greater detail into the importance of changes observed within time. Normalized gain shows student growth with respect to total possible growth given their average starting point. Normalized gain values $<0.3$ indicate small gains, while values $>0.7$ suggest large gains [46]. Effect size, on the other hand, incorporates standard deviation to compute the overall effect of the intervention, with ranges for small ( 0.2), medium ( 0.5), and large ( 0.8) effect sized [47]. Effect size has no upper margin, though effect sizes are commonly less than 2 [48]. Overall attitude of participants in the treatment group was improved by a normalized gain factor of 0.15 with a small effect size (Hedge's $g=0.35$ ). Effect size calculation in all categories of the CLASS resulted in a Hedge's g between 0.2 to 0.4 . Positive 
effect size measured in the treatment group indicates that YouTube pedagogy did not show any negative influence for students learning Engineering (Table 4).

\section{Conclusion}

Students-written problems were implemented to replace traditional textbook problems. Previous studies demonstrated that YouTube pedagogy possesses potential for engaging and promoting students' problem-solving skills. However, changes in teaching styles may affect learning attitudes in addition to problem solving skills. Thus, the impact of replacing textbook problems with YouTube problem on learning attitudes was explored. An established survey, CLASS, measured learning attitudes in a pre/post manner. CLASS responses, from one academic year with students undergoing YouTube pedagogy, revealed that majority of students had positive attitudes at the start of the semester. By the end of the semester, attitudes toward learning chemical engineering concepts increased slightly in most categories and range of responses became smaller. Furthermore, positive attitude gains led to a small effect within a 15-week semester for participants that completed YouTube problems. Additional data collected for another academic year will help corroborate findings.

\section{Acknowledgments}

This material is based upon work supported by the National Science Foundation under Grant No. DUE 1712186. Any opinions, findings, and conclusions or recommendations expressed in this material are those of the author(s) and do not necessarily reflect the views of the National Science Foundation. This work was completed within the framework of University of Toledo protocol 202214.

\section{References}

1. Crimson. Top 10 Jobs in 2030: Skills You Need Now to Land the Jobs of the Future: Future Skills. $2018 \quad$ [cited 2019 January]; Available from: https://www.crimsoneducation.org/us/blog/jobs-of-the-future.

2. Vest, C.M., Infusing Real World Experiences into Engineering Education. 2012.

3. Daigger, G.T., et al., Real World Engineering Education Committee. 2012.

4. Hawkins, J. and S. Blakeslee, On intelligence. 2005: St. Martin's Griffin.

5. Tasker, R. and R. Dalton, Research into practice: visualisation of the molecular world using animations. Chemistry Education Research and Practice, 2006. 7(2): p. 141-159.

6. Wen, F. and E. Khera, Identify Solve Broadcast your own transport phenomena: Student created YouTube videos to foster active learning in mass and heat transfer. Chemical Engineering Education, 2016. 50(3): p. 186-192.

7. Velazquez-Marcano, A., et al., The Use of Video Demonstrations and Particulate Animation in General Chemistry. Journal of Science Education and Technology, 2004. 13(3): p. 315324.

8. Liberatore, M.W., et al., Student-created homework problems based on YouTube videos. Chemical Engineering Education, 2013. 47(2): p. 122-132.

9. Medina, J., Brain Rules 12 Principles for Surviving and Thriving at Work, Home, and School. 2008: Pear Press. 
10. Brown, J.R. and M.B. McGrath, Visual learning for science and engineering. IEEE Comput Graph Appl, 2005. 25(5): p. 56-63.

11. Al-Balushi, S.M. and S.H. Al-Hajri, Associating animations with concrete models to enhance students' comprehension of different visual representations in organic chemistry. Chem. Educ. Res. Pract., 2014. 15(1): p. 47-58.

12. Doidge, N., The brain that changes itself: Stories of personal triumph from the frontiers of brain science. 2007: Penguin.

13. Doidge, N., The brain's way of healing: Remarkable discoveries and recoveries from the frontiers of neuroplasticity. 2016: Penguin Books.

14. Liberatore, M.W., Improved student achievement using personalized online homework for a couse in material and energy balances. Chemical Engineering Education, 2011. 45(3): p. 184190.

15. Liberatore, M.W., Active Learning and Just-in-time Teaching In a Material and Energy Balances Course. Chemical Engineering Education, 2013. 47(3): p. 154-160.

16. Liberatore, M.W., High textbook reading rates when using an interactive textbook for a Material and Energy Balances course. Chemical Engineering Education, 2017. 51(3): p. 109118.

17. Bullard, L.G. and R.M. Felder, A Student-Centered Approach To Teaching A StudentCentered Material and Energy Balances. 1. Course design. Chemical Engineering Education, 2007. 41: p. 93-100.

18. Bullard, L.G. and R.M. Felder, A Student-Centered Approach To Teaching A StudentCentered Material and Energy Balances. 2. Course delivery and assessment. Chemical Engineering Education, 2007. 41(3): p. 168-176.

19. Silverstein, D.L., L.G. Bullard, and M.A. Vigeant. How we teach: Material and Energy Balances. in ASEE Annual Meeting. 2012. San Antonio, TX.

20. Kennedy, G.E., et al., First year students' experiences with technology: Are they really digital natives? Australasian journal of educational technology, 2008. 24(1).

21. Roos, D., How Net Generation Students Work. 2007.

22. Lang, J.M., Small Teaching: Everyday Lessons from the Science of Learning. 2016: John Wiley \& Sons.

23. Freeman, S., et al., Active learning increases student performance in science, engineering, and mathematics. Proceedings of the National Academy of Sciences, 2014. 111(23): p. 84108415.

24. Falconer, J.L., Why not try active learning? Aiche Journal, 2016. 62(12): p. 4174-4181.

25. Arnaud, C.H., Active Learning Beats Lectures. Chemical \& Engineering News, 2014. 92(22): p. 31-31.

26. Liberatore, M.W., YouTube Fridays: Engaging the Net Generation in 5 Minutes a Week. Chemical Engineering Education, 2010. 44(3): p. 215-221.

27. Liberatore, M.W., C.R. Vestal, and A.M. Herring, YouTube Fridays: Student led development of engineering estimate problems. Advances in Engineering Education, 2012. 3(1): p. 1-16.

28. Liberatore, M., et al. Student-Generated Problems that Reverse Engineer YouTube Videos. in ASEE Annual Conference proceedings. 2018.

29. Duckett, T.R., et al., Assessing the Reliability of a Chemical Engineering Problem-solving Rubric when Using Multiple Raters, in ASEE annual conference \& exposition; 2019.

30. Asogwa, U., M.W. Liberatore, and A.P. Malefyt. Problem Solving When Using StudentWritten YouTube Problems. in ASEE Annual Conference \& Exposition. 2019. 
31. Donohue, S.K. and L.G. Richards. Factors affecting student attitudes toward active learning activities in a graduate engineering statistics course. in 2009 39th IEEE Frontiers in Education Conference. 2009. IEEE.

32. Uusimaki, L. and R. Nason, Causes Underlying Pre-Service Teachers' Negative Beliefs and Anxieties about Mathematics. International Group for the Psychology of Mathematics Education, 2004.

33. Goodykoontz, E.N., Factors that affect college students' attitude toward mathematics. 2008.

34. Haladyna, T., R. Olsen, and J. Shaughnessy, Correlates of class attitude toward science. Journal of Research in Science Teaching, 1983. 20(4): p. 311-324.

35. Maltese, A.V. and R.H. Tai, Pipeline persistence: Examining the association of educational experiences with earned degrees in STEM among US students. Science education, 2011. 95(5): p. 877-907.

36. Akpinar, E., et al., Students' attitudes toward science and technology: an investigation of gender, grade level, and academic achievement. Procedia-Social and Behavioral Sciences, 2009. 1(1): p. 2804-2808.

37. Ha, J.-Y., Learning style, learning attitude, and self-directed learning ability in nursing students. The Journal of Korean academic society of nursing education, 2011. 17(3): p. 355364.

38. Adams, W.K., et al., New instrument for measuring student beliefs about physics and learning physics: The Colorado Learning Attitudes about Science Survey. Physical review special topics-physics education research, 2006. 2(1): p. 010101.

39. Christensen, R., Effects of technology integration education on the attitudes of teachers and students. Journal of Research on technology in Education, 2002. 34(4): p. 411-433.

40. Lovelace, M. and P. Brickman, Best practices for measuring students' attitudes toward learning science. CBE_Life Sciences Education, 2013. 12(4): p. 606-617.

41. Douglas, K., et al., Evaluation of colorado learning attitudes about science survey. Physical Review Special Topics-Physics Education Research, 2014. 10(2): p. 020128.

42. Adams, W.K., et al., Modifying and validating the Colorado Learning Attitudes about Science Survey for use in chemistry. Journal of Chemical Education, 2008. 85(10): p. 1435.

43. Liberatore, M.W., Material and Energy Balances zyBook. 2020, Zybooks - a Wiley brand.

44. Semsar, K., et al., The Colorado learning attitudes about science survey (CLASS) for use in biology. CBE_-life sciences education, 2011. 10(3): p. 268-278.

45. Ellis, P.D., The essential guide to effect sizes: Statistical power, meta-analysis, and the interpretation of research results. 2010: Cambridge University Press.

46. Hake, R.R., Interactive-engagement versus traditional methods: A six-thousand-student survey of mechanics test data for introductory physics courses. American Journal of Physics, 1998. 66(1): p. 64.

47. Hedges, L.V., Distribution theory for Glass's estimator of effect size and related estimators. journal of Educational Statistics, 1981. 6(2): p. 107-128.

48. Rosenthal, R., H. Cooper, and L. Hedges, Parametric measures of effect size. The handbook of research synthesis, 1994. 621(2): p. 231-244. 